\title{
Efficacy of modified rubber band ligation in the treatment of grade III internal hemorrhoids
}

\author{
Lei Jin", Haojie Yang", Kaijian Qin, Ying Li, Can Cui, Renjie Wu, Zhenyi Wang, Jiong Wu \\ Department of Coloproctology, Yueyang Hospital of Integrated Traditional Chinese and Western Medicine, Shanghai University of Traditional \\ Chinese Medicine, Shanghai, China \\ Contributions: (I) Conception and design: L Jin, J Wu; (II) Administrative support: J Wu; (III) Provision of study material or patients: All authors; (IV) \\ Collection and assembly of data: All authors; (V) Data analysis and interpretation: L Jin; (VI) Manuscript writing: All authors; (VII) Final approval of \\ manuscript: All authors. \\ \#These authors contributed equally to this work. \\ Correspondence to: Jiong Wu; Zhenyi Wang. Department of Coloproctology, Yueyang Hospital of Integrated Traditional Chinese and Western \\ Medicine, Shanghai University of Traditional Chinese Medicine, Shanghai 200437, China. Email: tcmoctober9@163.com; drxinhuo@163.com.
}

Background: Traditional rubber band ligation can improve the symptoms of hemorrhoids, the techniques used vary among centers and the degree of hemorrhoids may also affect the therapeutic efficacy and postoperative outcome, especially for patients with grade III hemorrhoids (hemorrhoid prolapses). This study aimed to investigate the clinical efficacy of modified rubber band ligation (MRBL) in the treatment of grade III internal hemorrhoids.

Methods: A total of 120 patients with grade III internal hemorrhoids were randomly assigned to receive MRBL or Milligan-Morgan haemorrhoidectomy (MMH) ( $\mathrm{n}=60$ per group). The post-operative pain, bleeding, urine retention and feeling of anal distension were recorded, and the resting anal pressure (RAP) and post-operative recurrence rate were compared between two groups.

Results: The post-operative pain, bleeding and urine retention in the MRBL group were improved significantly as compared with the $M M H$ group $(\mathrm{P}<0.05)$, but the feeling of anal distension was similar between them $(\mathrm{P}>0.05)$. The RAP remained unchanged after MRBL, but the RAP at 1 month after surgery in the $\mathrm{MMH}$ group increased markedly $(\mathrm{P}<0.01)$ as compared with that before surgery and was significantly higher than that in the MRBL group $(\mathrm{P}<0.01)$. The post-operative recurrence rate was comparable between two groups $(\mathrm{P}>0.05)$.

Conclusions: As compared with traditional MMH, MRBL is effective to attenuate the post-operative pain and other discomforts and stabilize the RA. Thus, MRBL is an ideal choice for the treatment of grade III internal hemorrhoids.

Keywords: Rubber band ligation; modified technique; Milligan-Morgan haemorrhoidectomy; grade III internal hemorrhoids

Submitted Dec 24, 2019. Accepted for publication Sep 02, 2020.

doi: 10.21037/apm-19-657

View this article at: http://dx.doi.org/10.21037/apm-19-657

\section{Introduction}

Since Thomson proposed the concept of "anal cushion" (1), people have realized that hemorrhoids are caused by the alteration of anorectal anatomic structures in humans. When the venous drainage of the anus is altered, the venous plexus and connecting tissue will dilate, creating an outgrowth of anal mucosa from the rectal wall, which causes the formation of hemorrhoids and a series of symptoms (2). In 1954, Blaisdell for the first time attempted to treat internal hemorrhoids with rubber band ligation. After 
9 years, Barron improved this method, achieving favorable efficacy (3). In the traditional rubber band ligation, a small rubber band is placed at the base and then released. The constricting bands remain in place until they eventually fall off. In respect of the anatomic structure of the hemorrhoids, rubber band ligation has its own advantages (it can preserve the anal function). However, although this treatment can improve the symptoms of hemorrhoids, the techniques used vary among centers and the degree of hemorrhoids may also affect the therapeutic efficacy and post-operative outcome, especially for patients with grade III hemorrhoids (hemorrhoid prolapses) (4,5). In the present study, we modified the traditional rubber band ligation for the treatment of grade III hemorrhoids, in which an elastic coil was used to ligate the hemorrhoid. Herein, we reported the clinical efficacy of modified rubber band ligation (MRBL). We present the following article in accordance with the CONSORT reporting checklist (available at http://dx.doi. org/10.21037/apm-19-657).

\section{Methods}

\section{Patients}

A total of 120 patients with grade III hemorrhoid were recruited from the Department of Coloproctology, Yueyang Hospital of Integrated Traditional Chinese and Western Medicine, Shanghai University of Traditional Chinese Medicine between May 2017 and September 2017. The age ranged from 18 years to 65 years. Exclusion criteria were as follows: patients received treatments with other instruments or surgery within prior 6 months; patients had acute infectious diseases (active hepatitis B, Treponema pallidum antibody $>+1: 8$, positive for human immunodeficiency virus); the fasting blood glucose was $\geq 8 \mathrm{mmol} / \mathrm{L}$; patients had severe anemia $(\mathrm{Hb}<60 \mathrm{~g} / \mathrm{L})$; patients had coagulation disorders; menstrual or pregnant women or those with other severe diseases were also excluded. In addition, patients who developed serious adverse events, complications or other special diseases and those who had incomplete clinical records which affected the determination of clinical efficacy and safety were also excluded from this study. Patients were randomly assigned to receive MRBL or Milligan-Morgan haemorrhoidectomy (MMH) (n=60 per group). The study was conducted in accordance with the Declaration of Helsinki (as revised in 2013). The study was approved by institutional ethics board of Yueyang Hospital of Integrated Traditional Chinese and Western Medicine, Shanghai
University of Traditional Chinese Medicine (No. 2016-099) and informed consent was taken from all the patients.

\section{Therapeutic procedures}

All the patients received routine blood test, routine stool test, and detections of liver function, kidney function, fasting blood glucose, prothrombin time, Treponema pallidum antibody, hepatitis B virus antibodies and HIV antibody, and electrocardiography, aiming to exclude the contradictions to surgery. The resting anal pressure (RAP) was measured before surgery. The surgery was performed by the experienced surgeons.

The procedures for MRBL: The patient was placed in a right lateral position. After intravenous anesthesia and routine disinfection, the hemorrhoids were directly localized under the oblique transparent anal endoscope and graded. Based on the severity of hemorrhoid prolapse, the areas for ligation were determined (a total of 3 to 4 areas). The mucosa (greater than $1 \mathrm{~cm}$ in width) remained intact between the adjacent two area. The mucosa above the anal cushion (hemorrhoid) in the prolapsed area is subjected to vertical ligation at different sites, and the hanging position of each area was 1 and $3 \mathrm{~cm}$ directly above the dentate line. The instrument with disposable elastic band (Well, Wuhan Medical Technology Co., Ltd., B-6H) was used for the hemorrhoid ligation. The mucosa and submucosal tissues were suctioned into the instrument, but the suction of the muscular tissues should be avoided. The negative pressure was $-0.1 \mathrm{MPa}$. In this way, the affected area close to the dentate line was firstly ligated, and then the affected areas distant to the dentate line. After ligation, anus was examined for bleeding and stenosis. Once the hemorrhoid retracted well, the anus was filled with hemostatic sponge and an exhaust tube. The external anus was covered with gauzes which were fixed with tapes (Figure 1).

Procedures for MMH: Preoperative disinfection was above mentioned. After disinfection, the prolapsed hemorrhoid was clamped and lifted up, and the mucosa was separated with a high-frequency electric knife along the boundary between the base of hemorrhoid and the normal mucosa from the lower part of dentate line to the root of hemorrhoid above the dentate line. Deep separation should be avoided, or it could damage the internal sphincter. When the operation site was close to the dentate line, the incision should be done inward as more as possible, avoiding the removal of excessive normal mucosa. When the root of the 


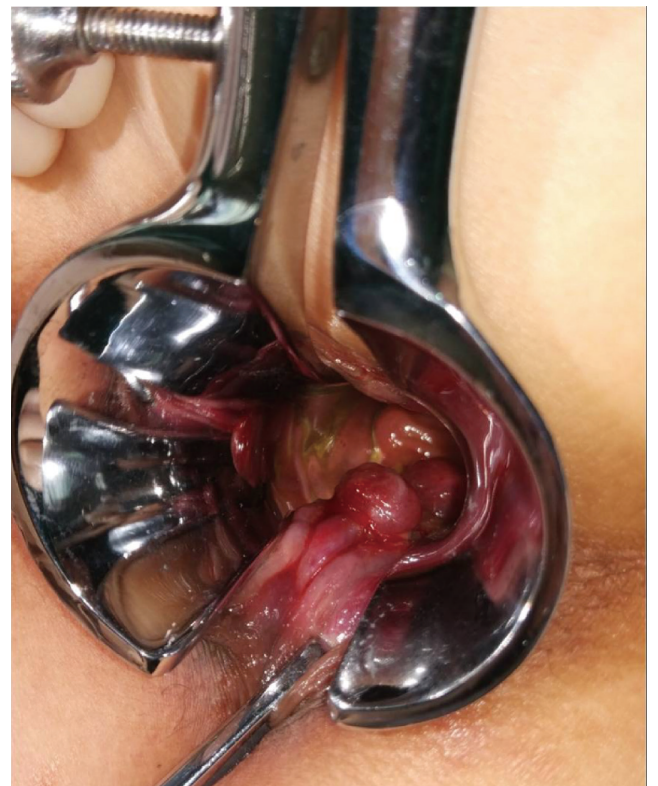

Figure 1 Vertical ligation of the mucosal tissue $1 \mathrm{~cm}$ and $3 \mathrm{~cm}$ directly above the dentate line.

internal hemorrhoid was separated, ligation was done with a suture. If the base of the hemorrhoid was too large, the suture run through the hemorrhoid, which was then ligated. At least 1-cm normal anorectal mucosa should be preserved at the wound after removal of the hemorrhoid. After the operation, the suture for ligation was fastened, the wound was examined for active bleeding and stenosis. Then, the anus was filled with hemostatic cotton and an exhaust tube. Finally, the anus was covered with gauzes, which were fixed with tapes.

All patients were asked to stay in bed within $24 \mathrm{~h}$ after surgery and the defecation was strictly controlled. After $24 \mathrm{~h}$, normal defecation was allowed. Routine clinical care, diet adjustment, hip bathing and postoperative analgesia (oral or intramuscular) were performed after surgery.

The primary outcome was 1-year recurrence rate. The secondary outcomes included postoperative anal pain, anal bleeding, urinary retention, feeling of anal distension, and postoperative RAP. The postoperative anal pain was evaluated with the visual analog scale (VAS) at $24 \mathrm{~h}, 1$ day, 3 days, 7 days and 14 days after surgery. Bleeding was evaluated at 24 h, 1 day, 3 days, 7 days, and 14 days after surgery. Criteria for evaluation: no bleeding; mild bleeding (staxis in dressing); moderate bleeding (drops of blood or ejection of blood, and hemostatic medication required); severe bleeding (heavy blood in the stool, and suture or surgical intervention needed). Urinary retention was evaluated at 24 h, 1 day, and 3 days after surgery. Criteria for evaluation: no urinary retention (patent urination after surgery); mild urinary retention (difficult urination which resolved spontaneously after use of hot compress at the bladder area; moderate urinary retention (dysuria which was resolved after muscular injection of neostigmine); severe urinary retention (urinary catheterization was required). The postoperative feeling of anal distension was evaluated at 24 h, 1 day, 3 days, 7 days and 14 days after surgery. Criteria for evaluation: no feeling of anal distension; mild feeling of anal distension (slight sensation of anal distension); moderate feeling of anal distension (obvious sensation of anal distension which resolved after resting); severe feeling of anal distension (serious and persistent sensation of anal distension which affected daily life).

The RAP was measured before surgery and 1 month after surgery in all the patients.

The patients were followed up via telephone at 1 month, 6 months, and 12 months after surgery. They were followed up for repeated bleeding and symptoms of hemorrhoids prolapsing. The presence of one manifestation was indicative of recurrence.

\section{Statistical analysis}

Data with normal distribution are expressed as mean \pm standard deviation $(\bar{x}+s)$, and those with abnormal distribution are expressed as median and quartile range. Quantitative variables were compared using the independent $t$ test or Mann-whitney $U$ test between two groups. Chi-square test is used for the comparisons of qualitative variables. The recurrence rate was analyzed by calculating the cumulative incidence. A value of $\mathrm{P}<0.05$ was considered statistically significant. Statistical analysis was performed using the SPSS version 21.0 and GraphPad Prism 5.

\section{Results}

The baseline characteristics of patients in two groups are shown in Table 1 (gender, age, and pre-operative RAP).

\section{Post-operative secondary outcomes}

At 24 h, 1 day, 3 days, 7 days and 14 days, the anal pain was improved significantly in the MRBL group and markedly better than in the $M M H$ group $(\mathrm{P}<0.01)$ (Figure 2). At 1 day, 
Table 1 Demographic and clinical characteristics of patients in two groups

\begin{tabular}{lccc}
\hline Characteristics & $\begin{array}{c}\text { Modified RBL } \\
(\mathrm{N}=60)\end{array}$ & $\mathrm{M}-\mathrm{M}(\mathrm{N}=60)$ & $\mathrm{P}$ \\
\hline Male/female & $25 / 35$ & $28 / 32$ & 0.58 \\
Age, y & $47.92 \pm 13.90$ & $52.33 \pm 10.64$ & 0.053 \\
RAP $(\mathrm{mmHg})$ & $64.84 \pm 9.46$ & $66.22 \pm 8.89$ & 0.41 \\
\hline
\end{tabular}

There were no marked differences in the age, gender and preoperative RAP between two groups $(P>0.05)$.

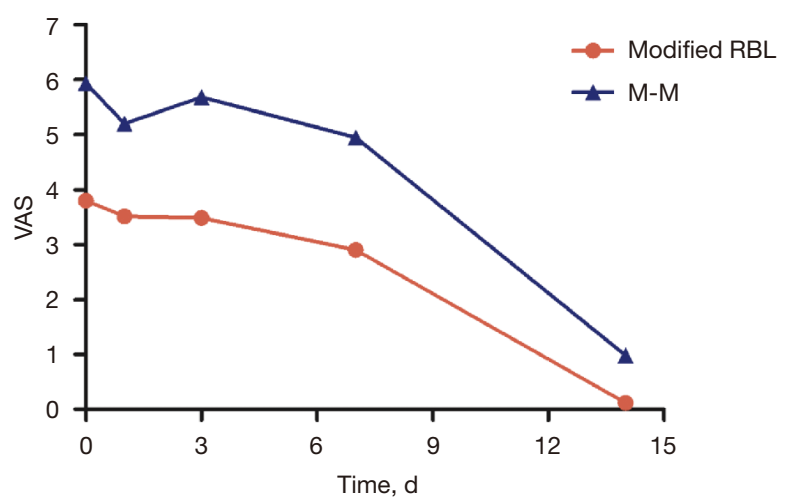

Figure 2 VAS score at different time points after surgery in two groups.

3 days and 7 days after surgery, the post-operative bleeding was markedly improved in the MRBL group as compared with the MMH group $(\mathrm{P}<0.05)$. At $24 \mathrm{~h}(\mathrm{P}=0.65)$ and 14 days $(\mathrm{P}=0.28)$ after surgery, the bleeding was similar between two groups (Table 2). The post-operative feeling of anal distension in the MRBL group was superior to that in the $M M H$ group although no significant difference was noted between them $(\mathrm{P}>0.05)$ (Table 3). Difficult urination of different extents was observed in both groups after surgery, but the urinary retention in the MRBL was improved significantly as compared with the MMH group $(\mathrm{P}<0.05)$ (Table 4).

\section{Post-operative RAP}

In the MRBL group, the RAP remained stable after surgery $(\mathrm{P}>0.05)$. At 1 month after surgery, the RAP was significantly higher than that before surgery in the $M M H$ group $(\mathrm{P}<0.01)$, and it in the MMH group was also markedly higher than in the MRBL group $(\mathrm{P}<0.01)$ (Table 5).
Table 2 Postoperative bleeding in two groups

\begin{tabular}{ccccccc}
\hline \multirow{2}{*}{ Group } & $\mathrm{N}$ & $\begin{array}{c}\text { Time } \\
\text { point }\end{array}$ & $\begin{array}{c}\text { No } \\
\text { bleeding }\end{array}$ & Mild & Medium & Severe \\
\hline MRBL & 60 & $24 \mathrm{~h}$ & 56 & 3 & 1 & 0 \\
& & $1 \mathrm{~d}$ & 33 & 27 & 0 & 0 \\
& & $3 \mathrm{~d}$ & 44 & 16 & 0 & 0 \\
& & $7 \mathrm{~d}$ & 27 & 30 & 3 & 0 \\
& & $14 \mathrm{~d}$ & 59 & 1 & 0 & 0 \\
M-M & 60 & $24 \mathrm{~h}$ & 54 & 2 & 4 & 0 \\
& & $1 \mathrm{~d}$ & 19 & 38 & 3 & 0 \\
& & $3 \mathrm{~d}$ & 22 & 36 & 2 & 0 \\
& & $7 \mathrm{~d}$ & 14 & 39 & 6 & 1 \\
& & $14 \mathrm{~d}$ & 51 & 9 & 0 & 0 \\
\hline
\end{tabular}

Number of patients with anal bleeding at different time points after surgery in two groups.

Table 3 Postoperative feeling of anal distention in two groups

\begin{tabular}{lcccccc}
\hline Group & $\mathrm{N}$ & Time & $\begin{array}{c}\text { No anal } \\
\text { distention }\end{array}$ & Mild & Medium & Severe \\
\hline Modified & 60 & $24 \mathrm{~h}$ & 44 & 16 & 0 & 0 \\
RBL & & $1 \mathrm{~d}$ & 33 & 27 & 0 & 0 \\
& & $3 \mathrm{~d}$ & 24 & 26 & 10 & 0 \\
& & $7 \mathrm{~d}$ & 24 & 36 & 0 & 0 \\
& & $14 \mathrm{~d}$ & 59 & 1 & 0 & 0 \\
M-M & $24 \mathrm{~h}$ & 39 & 20 & 1 & 0 \\
& & $1 \mathrm{~d}$ & 26 & 31 & 3 & 0 \\
& & $3 \mathrm{~d}$ & 17 & 30 & 12 & 1 \\
& & $7 \mathrm{~d}$ & 20 & 36 & 4 & 0 \\
& & $14 \mathrm{~d}$ & 55 & 5 & 0 & 0 \\
\hline
\end{tabular}

Number of patients with post-operative feeling of anal distension at different time points after surgery in two groups.

\section{Recurrence rate within 1 year}

None was lost to follow up in two groups, and serious adverse effects were not observed in two groups. In the MRBL group, 1 patient developed bloody stool (mild bleeding), and 3 patients developed prolapsing hemorrhoid which could be reduced spontaneously. In the MMH group, 2 patients developed blood stool (mild bleeding). 
Table 4 Postoperative urinary retention in two groups

\begin{tabular}{lcccccc}
\hline Group & $\mathrm{N}$ & Time & $\begin{array}{c}\text { No urinary } \\
\text { retention }\end{array}$ & Mild & Medium & Severe \\
\hline Modified & 60 & $24 \mathrm{~h}$ & 41 & 16 & 2 & 1 \\
RBL & & $1 \mathrm{~d}$ & 42 & 15 & 2 & 1 \\
& & $3 \mathrm{~d}$ & 53 & 6 & 0 & 1 \\
M-M & 60 & $24 \mathrm{~h}$ & 28 & 20 & 9 & 3 \\
& & $1 \mathrm{~d}$ & 30 & 19 & 8 & 3 \\
& & $3 \mathrm{~d}$ & 39 & 16 & 2 & 3 \\
\hline
\end{tabular}

Number of patients with post-operative urinary retention.

Table 5 Postoperative resting anal pressure in two groups

\begin{tabular}{lccc}
\hline Group & $\mathrm{N}$ & Time point & $\begin{array}{c}\text { Resting anal pressure } \\
(\bar{x}+\mathrm{s}, \mathrm{mmHg})\end{array}$ \\
\hline $\begin{array}{l}\text { Modified } \\
\text { RBL }\end{array}$ & 60 & Before surgery & $64.84 \pm 9.46$ \\
& 60 & $\begin{array}{c}\text { One month after } \\
\text { surgery }\end{array}$ & $64.75 \pm 8.88^{\# \#}$ \\
M-M & 60 & Before surgery & $66.22 \pm 8.89$ \\
& 57 & One month after & $71.09 \pm 7.63^{* *}$ \\
& & surgery & \\
\hline
\end{tabular}

At 1 month after surgery, the RAP was significantly higher than that before surgery in the $\mathrm{MMH}$ group $\left({ }^{* *} \mathrm{P}<0.01\right)$, and it in the $\mathrm{MMH}$ group was also markedly higher than in the MRBL group $\left({ }^{\# \#} \mathrm{P}<0.01\right)$.

The accumulated recurrence rate was similar between two groups (Figure 3).

\section{Discussion}

Our study showed the therapeutic efficacy after MRBL was similar to that after MMH for patients with grade III internal hemorrhoids at 1 year, but the post-operative pain, bleeding and urinary retention were improved significantly in the MRBL group as compared with the MMH group, and the feeling of anal distension was comparable after surgery after two treatments. In addition, the RAP remained stable after MRBL as compared with the MMH. Pain is the most common complication after surgery for hemorrhoids. In our study, modified ligation was done at the mucosa and submucosal tissues $1 \mathrm{~cm}$ and $3 \mathrm{~cm}$ away from the dentate line, which significantly reduced the postoperative pain. The rubber band ligation does not directly produce a wound, and the wound is gradually healed while the

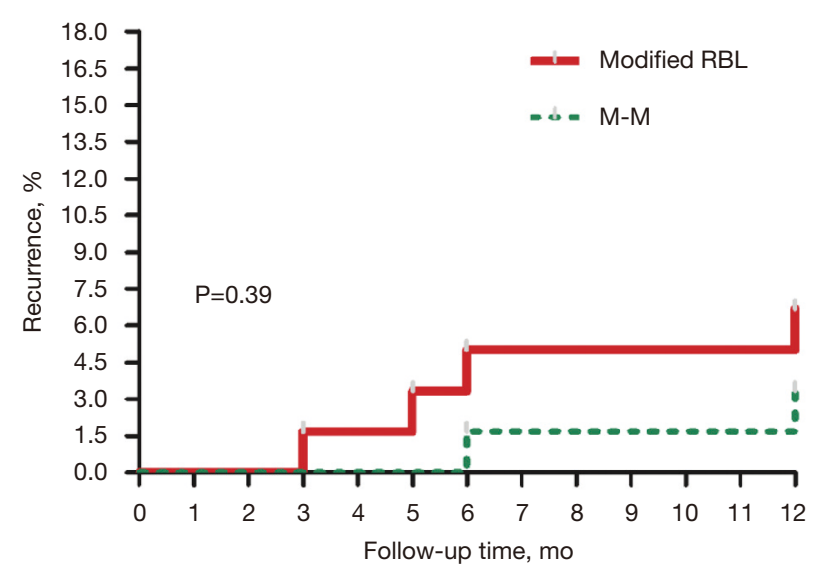

Figure 3 Number of patients with recurrence within 1 year in two groups.

necrotic tissues fall off. Thus, the bleeding after ligation is significantly better than that after the traditional surgery. Urinary retention is also a common complication of surgery for hemorrhoids. It has been reported that anesthesia, postoperative pain and fecal impaction are the risk factors for postoperative urinary retention $(6,7)$. In the study, the anesthesia and preoperative bowel preparation were identical between two groups. The postoperative pain was attenuated in the MRBL group, and thus the incidence of dysuria was relatively reduced. The causes of sensation of anal distension are various. The postoperative pain may cause the fecal retention, which induce long-lasting compression on the rectal nerves, causing the sensation of anal distension. In addition, the sensation of nerve retraction in the mucosal tissues is evident after surgery, which may also cause the sensation of anal distension. In the present study, more mucosal tissues were ligated, which may cause the nerve retraction, inducing the feeling of anal distension.

The anorectal pressure plays a crucial role in the defecation. Traditional surgery may cause the increase in the RAP due to the preservation of the skin bridge and postoperative scar contracture, which also increase the risk for anal canal stenosis, affecting the postoperative defection. However, the MRBL fails to destroy the anal canal epithelial area and maximize the function of the anus, and thus the postoperative RAP remains.

High postoperative recurrence rate is a common issue in the rubber band ligation. The post-operative recurrence rate varies significantly, depending on the surgical approaches, ligation instruments, and the severity 
of internal hemorrhoids (8-14). In addition, the criteria for postoperative recurrence have not been widely accepted. Shanmugam et al. (15) proposed a definition for postoperative recurrence, but this definition is inapplicable. Hemorrhoids are a group of benign diseases, and most clinicians speculate that the key to the successful treatment is the patient's subjective experience and no other surgical treatment (16-20). In the present study, the post-operative recurrence was defined as the presence of bloody stool or hemorrhoid prolapsing. In the MRBL group, only 2 patients developed blood stool or symptoms of hemorrhoid prolapsing within 1 year after surgery. Post-operative follow up showed these symptoms failed to significantly affect the quality of life in both patients, and thus further treatment was not administered. The vertical ligation was employed for the MRBL, which is in line with the biomechanical characteristics of the pelvic floor and the therapeutic efficacy is stable, which significantly reduces the postoperative recurrence.

There were still limitations in this study. This was a single-center study. The life-style adjustment was not controlled in these patients after surgery (such as diet and defecation), which may affect the long-term outcome. In addition, long term follow up is needed to determine the long term efficacy of MRBL.

\section{Conclusions}

The MRBL is effective to relieve post-operative pain and discomforts after surgery, and the therapeutic efficacy is similar to that of MMH. Thus, we speculate that MRBL is an ideal choice for the treatment of grade III internal hemorrhoids.

\section{Acknowledgments}

Funding: This study was supported by Shanghai Science and Technology Committee (STCSM) project (No. 18401904100).

\section{Footnote}

Reporting Checklist: The authors have completed the CONSORT reporting checklist. Available at http://dx.doi. org/10.21037/apm-19-657

Data Sharing Statement: Available at http://dx.doi. org/10.21037/apm-19-657
Conflicts of Interest: All authors have completed the ICMJE uniform disclosure form (available at http://dx.doi. org/10.21037/apm-19-657). The authors have no conflicts of interest to declare.

Ethical Statement: The authors are accountable for all aspects of the work in ensuring that questions related to the accuracy or integrity of any part of the work are appropriately investigated and resolved. The study was conducted in accordance with the Declaration of Helsinki (as revised in 2013). The study was approved by institutional ethics board of Yueyang Hospital of Integrated Traditional Chinese and Western Medicine, Shanghai University of Traditional Chinese Medicine (No.: 2016-099) and informed consent was taken from all the patients.

Open Access Statement: This is an Open Access article distributed in accordance with the Creative Commons Attribution-NonCommercial-NoDerivs 4.0 International License (CC BY-NC-ND 4.0), which permits the noncommercial replication and distribution of the article with the strict proviso that no changes or edits are made and the original work is properly cited (including links to both the formal publication through the relevant DOI and the license). See: https://creativecommons.org/licenses/by-nc-nd/4.0/.

\section{References}

1. Thomson WH. The nature of haemorrhoids. Br J Surg 1975;62:542-52.

2. Loder PB, Kamm MA, Nicholls RJ, et al. Haemorrhoids: pathology, pathophysiology and aetiology. Br J Surg 1994;81:946-54.

3. Barron J. Office ligation of internal hemorrhoids. Am J Surg 1963;105:563-70.

4. Gagloo MA, Hijaz SW, Nasir SA, et al. Comparative study of hemorrhoidectomy and rubber band ligation in treatment of second and third degree hemorrhoids in kashmir. Indian J Surg 2013;75:356-60.

5. Lu LY, Zhu Y, Sun Q. A retrospective analysis of short and long term efficacy of RBL for hemorrhoids. Eur Rev Med Pharmacol Sci 2013;17:2827-30.

6. Kameda K, Nakasone H. Urinary Retention due to Constipation. Intern Med 2016;55:2519.

7. Rashidi L, Gajjar AH. Identification of risk factors for postoperative urinary retention after various hemorrhoidrelated procedures. J Am Coll Surg 2014;219:e79-e80.

8. Brown SR, Tiernan JP, Watson AJM, et al. Haemorrhoidal 
artery ligation versus rubber band ligation for the management of symptomatic second-degree and thirddegree haemorrhoids (HubBLe): a multicentre, open-label, randomised controlled trial. Lancet 2016;388:356-64.

9. Shehata A, Saleh A, El-Heeny A. Clinical Outcome after Doppler-Guided Hemorrhoidal Artery Ligation and Rubber Band Ligation for Treatment of Primary Symptomatic Hemorrhoids. Indian J Surg 2019;81:332-7.

10. Brown SR, Watson A. Comments to 'Rubber band ligation versus excisional haemorrhoidectomy for haemorrhoids'. Tech Coloproctol 2016;20:659-61.

11. Ramzisham AR, Sagap I, Nadeson S, et al. Prospective randomized clinical trial on suction elastic band ligator versus forceps ligator in the treatment of haemorrhoids. Asian J Surg 2005;28:241-5.

12. Misauno MA, Usman BD, Nnadozie UU, et al. Experience with rubber band ligation of hemorrhoids in northern Nigeria. Niger Med J 2013;54:258-60.

13. Jutabha R, Jensen DM, Chavalitdhamrong D. Randomized prospective study of endoscopic rubber band ligation compared with bipolar coagulation for chronically bleeding internal hemorrhoids. Am J Gastroenterol 2009; 104:2057-64.

14. Nikam V, Deshpande A, Chandorkar I, et al. A prospective study of efficacy and safety of rubber band ligation in the treatment of Grade II and III hemorrhoids - a western

Cite this article as: Jin L, Yang H, Qin K, Li Y, Cui C, Wu R, Wang Z, Wu J. Efficacy of modified rubber band ligation in the treatment of grade III internal hemorrhoids. Ann Palliat Med 2021;10(2):1191-1197. doi: 10.21037/apm-19-657
Indian experience. J Coloproctol 2018;38:189-93.

15. Shanmugam V, Thaha MA, Rabindranath KS, et al. Rubber band ligation versus excisional haemorrhoidectomy for haemorrhoids. Cochrane Database Syst Rev 2005;(3):CD005034.

16. Bursics A, Morvay K, Kupcsulik P, et al. Comparison of early and 1-year follow-up results of conventional hemorrhoidectomy and hemorrhoid artery ligation: a randomized study. Int J Colorectal Dis 2004;19:176-80.

17. Denoya PI, Fakhoury M, Chang K, et al. Dearterialization with mucopexy versus haemorrhoidectomy for grade III or IV haemorrhoids: short-term results of a doubleblind randomized controlled trial. Colorectal Dis 2013;15:1281-8.

18. Wilkerson PM, Strbac M, Reece-Smith H, et al. Dopplerguided haemorrhoidal artery ligation: long-term outcome and patient satisfaction. Colorectal Dis 2009;11:394-400.

19. Shanmugam V, Muthukumarasamy G, Cook JA, et al. Randomized controlled trial comparing rubber band ligation with stapled haemorrhoidopexy for Grade II circumferential haemorrhoids: long-term results. Colorectal Dis 2010;12:579-86.

20. Elmer SE, Nygren JO, Lenander CE. A randomized trial of transanal hemorrhoidal dearterialization with anopexy compared with open hemorrhoidectomy in the treatment of hemorrhoids. Dis Colon Rectum 2013;56:484-90. 